Kalpa Publications in Engineering
Volume 3, 2020, Pages 49-56
Proceedings of International Sym-
posium on Applied Science 2019

\title{
Examining the Relationship Between Information Evaluation and Security Stock Level
}

\author{
Csaba Imre Hencz ${ }^{1 *}$ and Tamás Hartványi ${ }^{1 \dagger}$ \\ ${ }^{1}$ Széchenyi István University, Györ, Hungary. \\ hencz@sze.hu, hartvanyi@sze.hu
}

\begin{abstract}
In this research we intend to present a novel mathematical approach to logistics which allows (financial) value to be associated with information as a central corporate resource.

The inherent logistics processes (transport, production, sales) uncertainty requires continuous inventory monitoring and maintenance of safety stock levels. Literature and practice show that logistics responds to poor quality or incomplete information by increasing inventory.

In our research, we are looking for a minimum of safety stock levels based on the processing of information available in space and time and I intend to give a formal description of the mathematical model and present an example of its application.
\end{abstract}

\section{Introduction}

As early as the $50^{\prime}$ and $60^{\prime}$, Forrester realized that stochastic shifts in market demand were causing major shifts in logistics supply chains. (Forrester, 1961)

Companies are trying to mitigate these fluctuations when they cannot handle their information systems using various transformation tools.

If we do not have relevant information - and no opportunity to objectively know reality - there is no other option than to compensate for the missing information.

The compensation may take the form of:

- transforming material assets into information through purchase or monitoring, or

- converting time into information, where time provides an opportunity for more detailed knowledge, or

- $\quad$ transformation of other resources, typically stocks.

\footnotetext{
* Masterminded EasyChair and created the first stable version of this document

${ }^{\dagger}$ Created the first draft of this document
} 
In logistics, transformation is typically stock. That is, if there is no information about my environment, for example, increasing the stock level could mean ensuring the continuous operation of the company.

\section{Problem Determination}

It seems that the corporate systems of the transformation mechanisms are well handled automatically. Continuously adjusting inventory levels and organizing work schedules by reviewing forecasting methods and historical data.

The goal is to further improve this process by providing accurate information to the processing system so that:

- reduce the human time needed to make decisions,

- reduce inventory.

Advanced logistics systems are also based on well-known supply chain and corporate processes. In this way it is possible to automatically reduce the resources.

If I have good information, I can cut down on time, supplies and manpower. If this is not correct, the corporate systems are forced to auto-corrections.

This type of adjustment is usually done by the logistics organization by increasing the inventory. This is a value that is visible, quantifiable, and traceable in corporate processes.

It follows that we do not directly quantify information because it is essentially elusive, but indirectly, we can determine the value of transformed resources.

Not all information will force the logistics system to transform, but whichever is so, its value can be determined by this method.

With good information, the reduction in inventory rotation speed or volume can be clearly quantified.

Even though where good information is available, companies do not use such models. The reason is that:

- the cost of obtaining the information is uneconomic or

- this context is not known to decision makers.

Therefore, it is worthwhile to take economically useful and meaningful steps to make this information accessible.

\section{The Relationship Between Transformation and the Goodness of Information}

In the following, we intend to introduce a novel mathematical approach, through the study of stocks, which allows the (partly) elusive information to be associated with (financial) value.

As mentioned above, both the literature and practice show that logistics respond to low quality or incomplete information by increasing inventory. Therefore, we are constantly moving away from the "ideal" state known in our view as a saw tooth model. 


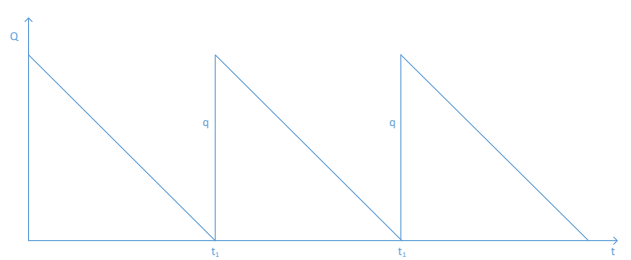

Figure 1. Sawtooth model

In this model, there is no need for safety stock.

Weight loss is steady, arrivals are constant in size and pace. In reality, it is relatively infrequent, but it is a good starting point for describing later stock models.

The inherent processes (supply, production, sales) uncertainty requires industrial operators, in addition to continuously maintain safety stock inventory monitoring.

In our investigations, the minimum security stock (Qmin) is considered to be an ideal stock level that can be reached after processing information available in space and time, ideally Qmin $=0$.

Safety Stock Maximum (Qmax) refers to the "normal" security level defined by inventory models from historical data.

This determination has developed an information system for the identification and production system does not pose a problem because the historical data can be easily collected, the date and time data are usually registered for each transaction type. (Akkermans, et all. 2003)

In our view, the practice of safety stock can not be left out entirely, however, the effect could be reduced with proper management of information management.

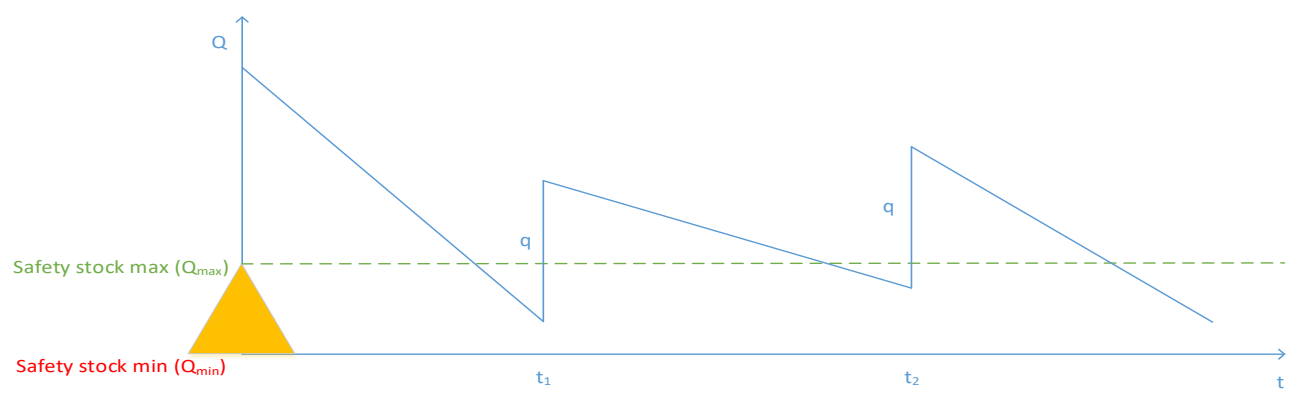

Figure 2. The relationship between "good" information and security stock levels

In our view, the value of "good" information is equal to the cost of the extra stock held for uncertainty. Starting from this, we can determine the value of the information.

Basic mathematical relationship (based on EOQ model) in the literature to determine the value of stocks:

where:

$$
K=\frac{q}{2} \cdot K_{k} \cdot t
$$

$$
\begin{aligned}
& \mathrm{K}=\text { cost of inventory [EUR] } \\
& \mathrm{q}=\text { order quantity [pcs] } \\
& \mathrm{K}_{\mathrm{k}}=\text { Inventory cost [EUR / pcs } * \text { day] } \\
& \mathrm{t}=\text { denotes the test period [days]. }
\end{aligned}
$$

However, this basic mathematical relationships we need to add, since the definition of "value" of information can be defined as a result of more in-depth studies.

Therefore, further examination of the emphasis of the cost of inventory safety stocks. 
Most current inventory models are not looking for the lowest inventory cost (inventory + replacement + shortage cost) as the shortage cost is difficult to describe. In contrast, they examine the level of service at a given inventory level. (Hirkó, Bikás, Bajor, 2007)

In contrast to the above, we are curious as to what cost value the minimum security kit can achieve.

To do this, we need to look at the structure of costs associated with inventory, which is structured as follows:

(K) Inventory cost $=\left(\mathrm{K}_{\mathrm{F}}\right)$ Cost of the physical nature of inventories $+\left(\mathrm{K}_{\mathrm{P}}\right)$ Costs related to the financial value of inventories

\subsection{Cost of the physical nature of inventories}

Stocks related to the physical nature of the costs can be quite diverse, it greatly depends on the specific characteristics of the goods, which include:

- physical state

$\circ$ solid, liquid, airy, etc.

- dimension

○ weight, shape, temperature, etc.

- quantity

$$
\circ \quad \text { variety, batch size, etc. }
$$

The combination of these properties of the goods determines the type of storage, which in our case refers to the environment in which the goods are stored - eg tempering, guarding, special handling, etc. therefore greatly influences the development of inventory costs.

It is also important to consider the size of the batch sizes - the size of the batch size was also part of the EOQ model (Harris 1913) - since most of the warehouses - limited to my investigations on this type of warehouse - are rarely stored without unit load devices.

The $\mathrm{m} 3$ thus taken into account; $\mathrm{m} 2$; The small change in the values of $\mathrm{kg}$ does not appear in the inventory costs, it is only reflected in the financial fixed assets ratio.

Of course, there is a relationship between the amount of sets and the size of the bundle, the features of which are illustrated in the figure below:

management.

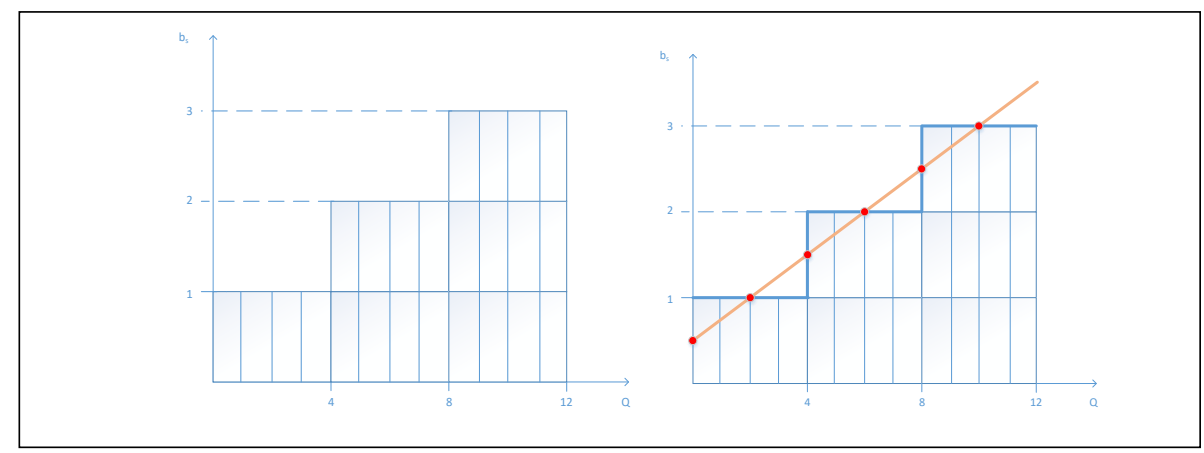

Figure 3. Relationship between batch size and stock quantity

So, for example, if we store four items per pallet, our inventory cost will not be reduced by selling one. In this example, the interpretation range of the function is discrete. Such functions are also called 
grid functions because they are interpreted only for specific discrete values. To define the bundle size we want to use in the model (where we denote the top integer), we write the following relationship:

where:

$$
b=\left\lceil\frac{Q}{b_{s}}\right\rceil
$$

$$
\begin{aligned}
& \mathrm{b}=\text { number of bundles [pcs] } \\
& \mathrm{Q}=\text { number of sets [pcs] } \\
& \mathrm{b}_{\mathrm{s}}=\text { bundle size [pcs] }
\end{aligned}
$$

In contrast, for modeling purposes, we will use continuous functions instead of discrete values. Thus, we can calculate values that can be interpreted over the entire interpretation range:

$$
b(t)_{a v e}=\frac{Q}{b_{s}}
$$

Thus, the function $b(t)$ now takes the following form:

$$
b(t)=\frac{Q(t)}{b_{s}}
$$

Taking into account the above, the following relationship can be established for the determination of the cost of the physical nature of inventories:

where:

$$
K_{F}=\sum_{u=1}^{n} F_{u} \cdot c_{u} \cdot b \cdot t
$$

$\mathrm{K}_{\mathrm{F}}=$ Cost of the physical nature of inventories

$\mathrm{F}_{\mathrm{u}}=$ Physical characteristic affecting storage [m3/batch; $\left.\mathrm{m} 2 / \mathrm{batch}, \mathrm{kg} / \mathrm{batch}\right]$

$\mathrm{c}_{\mathrm{u}}=$ Specific physical storage cost $[\mathrm{EUR} / \mathrm{m} 3 *$ year; EUR $/ \mathrm{m} 2 *$ year; EUR/kg * year $]$

$\mathrm{b}=$ Number of batches [pieces]

$\mathrm{t}=$ Storage time [days]

$* \mathrm{u}=$ items with different item numbers

The formula is modified as follows to add the description used to determine the batch size:

$$
K_{F}=\sum_{u=1}^{n} F_{u} \cdot c_{u} \cdot \int_{t_{1}}^{t_{2}} b(t) d t
$$

\subsection{Financial nature of inventories}

One of the main reasons used to justify financial investments in stocks is due to the volatility of demand. (Baganhaand, Cohen, 1998)

In contrast, the financial value of inventories is obtained by multiplying capital and interest.

Thus, the relationship between the cost of a financial commitment is determined as follows:

where:

$$
K_{P}=P \cdot i \cdot Q \cdot t
$$

$\mathrm{K}_{\mathrm{P}}=$ Cost of financially stockpiling inventories

$\mathrm{P}=$ Specific Cost of Inventory (Price) $[\mathrm{EUR} / \mathrm{pc}]$

$\mathrm{i}=$ interest rate (cost of acquisition or alternative use [\%/year]

$\mathrm{Q}=$ Quantity of stocks [pcs]

$\mathrm{t}=$ storage time [days/365]

integrating the formula gives the following relationship:

$$
K_{P}=\int_{t_{1}}^{t_{2}} Q(t) d t \cdot P \cdot i
$$

\section{Results}

To summarize the inventory cost: 
for a unit:

$$
K=K_{F}+K_{p}
$$

$$
K=\sum_{u=1}^{n} F_{u} \cdot c_{u} \int_{t_{1}}^{t_{2}} \frac{Q_{u}(t)}{b_{s_{u}}} d t+P \cdot i \int_{t_{1}}^{t_{2}} Q(t) d t
$$

Rearranging the formula, we find the following relationship:

$$
K=\left(P \cdot i+\sum_{u=1}^{n} \frac{F_{u} \cdot c_{u}}{b_{s_{u}}}\right) \cdot \int_{t_{1}}^{t_{2}} Q(t) d t
$$

In the event that I also consider the interest rate to be a constantly changing value, the formula changes as follows:

$$
K=\left(\int_{t_{1}}^{t_{2}} P \cdot i(t) d t+\sum_{u=1}^{n} \frac{F_{u} \cdot c_{u}}{b_{s_{u}}}\right) \cdot \int_{t_{1}}^{t_{2}} Q(t) d t
$$

Thus, the maximum return on good information (VImax) during stocking can be determined as follows:

$$
V_{I_{\text {max }}}=\left(\int_{t_{1}}^{t_{2}} P \cdot i(t) d t+\sum_{u=1}^{n} \frac{F_{u} \cdot c_{u}}{b_{s_{u}}}\right) \cdot \int_{t_{1}}^{t_{2}} Q(t) d t
$$

The formula above shows the maximum cost that can be saved by having the "good" information. This is true if the whole inventory process can be saved by having the information available. This can also be seen as a certain barrier that determines how much you should spend on obtaining information.

As inventory levels in logistics are constantly changing day by day and even hour by hour, existing information needs to be constantly reviewed. Thus, if the quality of information changes at a given $Q$ '(t) level, then the size of the inventory must follow the quality of the information to a $\mathrm{Q}^{\prime}(\mathrm{t})$ level (Q '(t) $\left.\rightarrow \mathrm{Q}^{\prime}(\mathrm{t})\right)$.

Currently, the size of safety stocks is determined by

- $\quad$ how much they are afraid of shortages (in our calculations, the example excerpt represents $98 \%$ service quality), and

- To what extent can they predict the future, ie what is the standard deviation $(\sigma)$ of stochastic processes?

Logistics models use the expected value of the dispersion of the distribution to predict the future.

In these stochastic models, the safety margin is calculated as follows:

$$
Q_{\text {safety } 1(98 \%)} \cong 2,05 \cdot \sigma_{1} \cdot \sqrt{L T}
$$

where:

Qsafety1 $(98 \%)=$ Security Inventory Level with 98\% Service Level

$\mathrm{LT}=$ lead time

$\sigma 1=$ standard deviation of the stochastic process

The availability of good information about increasing the probability density function describing the stochastic process variable changes as follows:

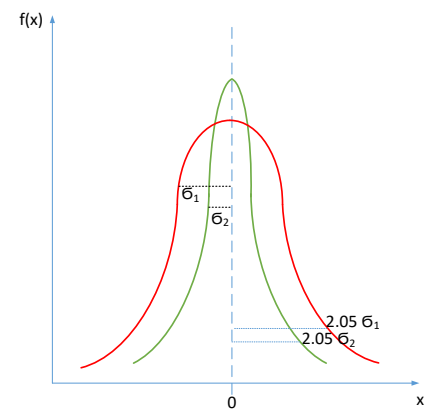


Figure 4. Modulator of random variable

Further to the above considerations, the size of the security stock is determined by the sum of the safety time determined by the turnaround time and past turnaround times and the stock turnover rate, ie:

where:

$$
K_{\text {safety }}=\left(L T+L T_{\text {safety }}\right) \cdot V_{\text {inventory }}
$$

$\mathrm{K}_{\text {safety }}=$ security inventory level [pcs]

$\mathrm{L}_{\mathrm{T}}=$ lead time [days]

$\mathrm{L}_{\text {Tsafety }}=$ security turnaround time [days]

$\mathrm{V}_{\text {inventory }}=$ Inventory Rotation Speed [pcs/day]

\section{Conclusions}

The following is a simple example of what I have done so far:

Assume an average lead time of 6 days ( $=6$ days).

The standard deviation of the arrivals is 1 day ( $\sigma=1$ day).

For $98 \%$ availability, in this case the size of the reorder point $=6+2.05 * 1=8.05$ days.

So in a very extreme case, in this example I can save 2.05 days by getting "good" information.

In the example, we would like to call attention to the proportionality that is one of the basic assumptions of the model,

- $\quad$ LT $\uparrow$ but $\sigma=0$ so Ksafety=0 if

- LT $\uparrow$ and $\sigma$ also $\uparrow$ so Ksafety also $\uparrow$.

Thus, as the information quality increases, the predictability of the occurrence of a given event increases. This will result in the expected value of the standard deviation decreasing, ie:

The new safety stock calculation:

$$
\sigma_{2}<\sigma_{1}
$$

$$
Q_{\text {safety } 2(98 \%)} \cong 2,05 \cdot \sigma_{2} \cdot \sqrt{L T}
$$

That is, the information supply leaving the other factors unchanged (ceteris paribus):

$$
Q_{\text {safety } 2} \cong Q_{\text {safety } 1} \cdot \frac{\sigma_{2}}{\sigma_{1}}
$$

Inventory costs are therefore reduced in proportion to the supply of "good" information:

$$
\frac{\sigma_{2}}{\sigma_{1}}<1
$$

The magnitude of this decrease in $\Delta \mathrm{Q}$ can be determined as follows:

$$
K=\left(\int_{t_{1}}^{t_{2}} P \cdot i(t) d t+\sum_{u=1}^{n} \frac{F_{u} \cdot c_{u}}{b_{S_{u}}}\right) \cdot-\int_{t_{1}}^{t_{2}} \Delta Q d t
$$

Since our goal is to determine the extent of inventory depreciation, we are looking for a negative value. The formula is further broken down into the following equation:

$$
\begin{gathered}
K=\left(\int_{t_{1}}^{t_{2}} P \cdot i(t) d t+\sum_{u=1}^{n} \frac{F_{u} \cdot c_{u}}{b_{S_{u}}}\right) \cdot-\Delta Q \cdot \int_{t_{1}}^{t_{2}} 1 d t \\
K=\left(\int_{t_{1}}^{t_{2}} P \cdot i(t) d t+\sum_{u=1}^{n} \frac{F_{u} \cdot c_{u}}{b_{S_{u}}}\right) \cdot-\Delta Q \cdot t
\end{gathered}
$$

Taking into account the above context, the percentage reduction that can be obtained by obtaining "good" information can be determined as follows:

$$
K_{\text {decrease }}=\frac{\Delta Q \cdot t}{K}
$$




\section{Summary}

We examined the resource management mechanism of corporate organizations.

We have found that organizations use other resources at their disposal instead of inadequate information.

We called this resource substitution a resource transformation.

Based on this relationship, the cost of the information gap was determined.

We have determined that the cost of obtaining the missing information can be at most equal to the value of the transformed resources.

\section{References}

Akkermans, H.A., Bogerd, P., Yücesan, E., van Wassenhove, L. N.: The impact of ERP on supply chain management: Exploratory findings from a European Delphi study, European Journal of Operational Research 146 (2003) pp. 284-301

Baganhaand, M.P., Cohen, M.A.:.The stabilising elect of inventory in supply chains. Operations Research, 46(3):572-583, 1998.

Harris, F.W.: How Many Parts To Make At Once, Factory, The Magazine of Management, 10(2), (1913) pp. 135-136, 152

Hirkó Bálint - Bikás Ernő - Bajor Péter (2007): Ellátási lánc menedzsment. I-II., Egyetemi jegyzet, Györ.

J. Forrester: Industrial Dynamics, Wiley, New York (1961) 